\title{
Paired-like homeodomain 2: a novel therapeutic target for atrial fibrillation?
}

\author{
Mengchao Yao ${ }^{1,2+}$, Yujie Cao ${ }^{1,2+}$, Hui Zhu ${ }^{1,2+}$, Yao Chen ${ }^{1,2}$, Tianhao Zhu ${ }^{1,2}$ and Junjie Xiao ${ }^{1,2,3 *}$ \\ ${ }^{1}$ Regeneration Lab and Experimental Center of Life Sciences, School of Life Science, Shanghai University, Shanghai, China \\ ${ }^{2}$ Shanghai Key Laboratory of Bio-Energy Crops, School of Life Science, Shanghai University, Shanghai, China \\ ${ }^{3}$ Innovative Drug Research Center of Shanghai University, Shanghai, China \\ *Correspondence: junjiexiao@live.cn \\ tThese authors have contributed equally to this work.
}

Edited by:

Saumya Das, Beth Israel Deaconess Medical Center/Harvard Medical School, USA

Reviewed by:

Michael Rosenberg, Veterans Administration Hospital System of Boston, USA

Keywords: atrial fibrillation, Pitx2, target, focal activity, reentry

Atrial fibrillation (AF), as a sustained arrhythmia, is featured by uncoordinated atrial activation with the consequent deterioration of mechanical function in the atrium (Mestroni, 2003; Fye, 2006; Fatkin et al., 2007; Otway et al., 2007). A large amount of risk factors for AF have been identified including ageing, male sex, hypertension, ischemic heart disease, myocardial infarction, valvular diseases, and obesity (Benjamin et al., 1994; Krahn et al., 1995; Go et al., 2001). AF can cause several serious complications including congestive heart failure and stroke (Wolf et al., 1991; Benjamin et al., 1998; Kannel et al., 1998; Mestroni, 2003; Piccini et al., 2012). As a most prevalent type of arrhythmia, AF has a life-time risk of 1 in 4 for those people aged over 40 in the United States and Europe (Lloyd-Jones et al., 2004; Donahue et al., 2005; Benjamin et al., 2009; Kim et al., 2011). Almost three million people in the United States are affected by AF, and the number is estimated to be doubled by year 2050 (Roberts and Gollob, 2010). In China, at least 10 million $\mathrm{AF}$ patients exist (Zhou and $\mathrm{Hu}$, 2008). Similar trends can also be observed in most other developed and developing countries worldwide (Tsai et al., 2008). AF has become a growing global problem. Dissecting the mechanisms and developing novel effective therapies for AF are highly desirable.

Three classical models have been proposed for the genesis of AF, including focal activity, single-circuit reentry, and multiple-circuit reentry model (Fatkin et al., 2007). The focal-activity hypothesis points out that $\mathrm{AF}$ is started and further driven by the rapid firing of single or multiple ectopic foci (Nattel, 2002; Xiao et al., 2011). The multiple-circuit reentry hypothesis assumes that several reentry circuits exist and randomly propagating wave fronts persist in receptive tissue while the single-circuit reentry hypothesis focuses on the interaction of a rotor with irregular waves in the atrium and "fibrillatory conduction," the spatially variable refractory properties of atrial tissue (Nattel, 2002; Xiao et al., 2011).

Although AF is a most prevalent type of arrhythmia, its genetic etiology remains unclear (Franco et al., 2011). At the very early beginning, AF is generally appreciated to be uninheritable (Xiao et al., 2011). Subsequently, $5 \%$ of AF patients and up to $15 \%$ of individuals with lone AF have been identified to have a familial history (Christophersen et al., 2013), which encourage the starting of genetic studies in familial form of AF. Besides that, the common variants in AF in the general population have been paid special attention with the recently published results from several large genome-wide association studies (GWAS) (Darbar et al., 2003; Fox et al., 2004; Christophersen et al., 2009; Sinner et al., 2011; Mahida, 2014). A susceptibility locus for AF on chromosome 4q25, which was reported in 2007 in the first GWAS for AF (Gudbjartsson et al., 2007) and has been independently replicated in multiple other association studies (Kaab et al., 2009; Sinner et al., 2011), is of highly interest. The identified signal at the $4 \mathrm{q} 25$ locus lies within an intergenic region without any currently known genes (Sinner et al., 2011; Mahida, 2014) and the closest gene, paired-like homeodomain 2 (Pitx2), is considered as a most promising candidate. Pitx2 is located 150,000 bases away and has been reported to contribute to cardiac development (Franco et al., 2011; Liu et al., 2012).

The Pitx2 gene mainly encodes three distinct isoforms including Pitx $2 a$, Pit $2 b$, and Pitx2c (Schweickert et al., 2000; Cox et al., 2002). A fourth isoform, Pitx2d is also expressed in human, functioning as a dominant negative protein (Cox et al., 2002). Pitx2 has been reported to participate to the establishment of leftright asymmetry of the heart (Lin et al., 1999). In addition, Pitx 2 plays a critical role in the development of the left atrium (Campione et al., 2001, 2002; Mommersteeg et al., 2007) and pulmonary vein myocardium as well (Mommersteeg et al., 2007). Interestingly, pulmonary vein is a source of AF (Nattel, 2002). Thus, inactivated Pitx2 may affect the development of pulmonary vein myocardium, contributing to ectopic electric activity from pulmonary vein. The loss-of-function of Pitx2 causes several severe cardiovascular defects, including atrial isomerism, double inlet left ventricle, abnormal aortic arch remodeling and transposition of the great arteries (Franco and Campione, 2003; Wang et al., 2013). Since the published of the identification of Pitx2 as a candidate in the first GWAS study, special attention has been paid to its potential role in AF. Knockout of Pitx2 in mice leads to pro-arrhythmogenic alterations in 
the action potential (Wang et al., 2010; Chinchilla et al., 2011; Kirchhof et al., 2011). The expression level of Pitx2c, a major form of Pitx2 in the adult heart, has been reported to be impaired in patients with AF (Chinchilla et al., 2011). Decreased Pitx2 leads to atrial electrical and structural remodeling (Chinchilla et al., 2011), both are arrhythmogenic alterations, and can finally increase susceptibility to atrial arrhythmias (Wang et al., 2010; Chinchilla et al., 2011; Kirchhof et al., 2011). Evidences show that the presence of common single nucleotide polymorphism (rs2200733, rs1033464) at the 4q25 locus (near Pitx2) is an independent predictor of AF recurrence after direct current cardioversion (Parvez et al., 2013). Moreover, rs 1033464 has also been reported as an independent predictor of successful rhythm control in antiarrhythmic drugs (Parvez et al., 2012). Although the putative function of Pitx2 in the fetal and adult heart is largely unknown, accumulating evidences show that defects in Pitx2 result in defects of cardiac conduction system (Franco et al., 2011), which might be a cause of spreading irregular waves and leads to AF. Promisingly, Pitx2 has been reported to prevent susceptibility to atrial arrhythmias through inhibition of left-sided pacemaker, such as the SAN-specific genetic program in left atrium (Wang et al., 2010), providing a novel therapeutic target for AF. A Pitx2 conditional knockout mouse which deletes Pitx2 in postnatal atrium but leaving the developmental function of Pitx2 intact exhibit the phenotype of irregular R-R interval with disappeared P-wave amplitude, indicating impaired atrial conduction (Tao et al., 2014). Thus, inactivated Pitx2 may also disrupt normal atrial conduction and thereafter promote rerentrant circuits. Accumulating evidence has indicated that Pitx2 is a promising therapeutic target for AF. Further understanding of the role of Pitx2 in the genesis of AF holds the potential to be eventually developed as a novel effective therapy for this common arrhythmia.

\section{ACKNOWLEDGMENTS}

This work was supported by the grants from National Natural Science Foundation of China (81200169 to Junjie Xiao), Innovation Program of Shanghai
Municipal Education Commission (13YZ014 to Junjie Xiao), Foundation for University Young Teachers by Shanghai Municipal Education Commission (year 2012, to Junjie Xiao) and Innovation Foundation of Shanghai University (sdcx2012038, to Junjie Xiao).

\section{REFERENCES}

Benjamin, E. J., Levy, D., Vaziri, S. M., Agostino, R. B. D., Belanger, A. J., and Wolf, P. A. (1994). Independent risk factors for atrial fibrillation in a population-based cohort. The Framingham Heart Study. JAMA 271, 840-844. doi: 10.1001/jama.1994.03510350050036

Benjamin, E. J., Rice, K. M., Arking, D. E., Pfeufer, A., van Noord, C., Smith, A. V., et al. (2009). Variants in ZFHX3 are associated with atrial fibrillation in individuals of European ancestry. Nat. Genet. 41, 879-881. doi: 10.1038/ng.416

Benjamin, E. J., Wolf, P. A., D'Agostino, R. B., Silbershatz, H., Kannel, W. B., and Levy, D. (1998). Impact of atrial fibrillation on the risk of death: the Framingham Heart Study. Circulation 98, 946-952. doi: 10.1161/01.CIR.98.10.946

Campione, M., Acosta, L., Martinez, S., Icardo, J. M., Aranega, A., and Franco, D. (2002). Pitx2 and cardiac development: a molecular link between left/right signaling and congenital heart disease. Cold Spring Harb. Symp. Quant. Biol. 67, 89-95. doi: 10.1101/sqb.2002.67.89

Campione, M., Ros, M. A., Icardo, J. M., Piedra, E., Christoffels, V. M., Schweickert, A., et al. (2001). Pitx2 expression defines a left cardiac lineage of cells: evidence for atrial and ventricular molecular isomerism in the iv/iv mice. Dev. Biol. 231, 252-264. doi: 10.1006/dbio. 2000.0133

Chinchilla, A., Daimi, H., Lozano-Velasco, E., Dominguez, J. N., Caballero, R., Delpon, E., et al. (2011). PITX2 insufficiency leads to atrial electrical and structural remodeling linked to arrhythmogenesis. Circ. Cardiovasc. Genet. 4, 269-279. doi: 10.1161/CIRCGENETICS.110.958116

Christophersen, I. E., Budtz-Jorgensen, E., Olesen, M. S., Haunso, S., Christensen, K., and Svendsen, J. H. (2013). Familial atrial fibrillation predicts increased risk of mortality: a study in Danish twins. Circ. Arrhythm. Electrophysiol. 6, 10-15. doi: 10.1161/CIRCEP.112.971580

Christophersen, I. E., Ravn, L. S., Budtz-Joergensen, E., Skytthe, A., Haunsoe, S., Svendsen, J. H., et al. (2009). Familial aggregation of atrial fibrillation: a study in Danish twins. Circ. Arrhythm. Electrophysiol. 2, 378-383. doi: 10.1161/CIRCEP.108.786665

Cox, C. J., Espinoza, H. M., McWilliams, B., Chappell, K., Morton, L., Hjalt, T. A., et al. (2002). Differential regulation of gene expression by PITX2 isoforms. J. Biol. Chem. 277, 25001-25010. doi: 10.1161/CIRCEP.108.786665

Darbar, D., Herron, K. J., Ballew, J. D., Jahangir, A., Gersh, B. J., Shen, W. K., et al. (2003). Familial atrial fibrillation is a genetically heterogeneous disorder. J. Am. Coll. Cardiol. 41, 2185-2192. doi: 10.1016/S0735-1097(03)00465-0
Donahue, J. K., Kikuchi, K., and Sasano, T. (2005). Gene therapy for cardiac arrhythmias. Trends Cardiovasc. Med. 15, 219-224. doi: 10.1016/j.tcm.2005.06.007

Fatkin, D., Otway, R., and Vandenberg, J. I. (2007). Genes and atrial fibrillation: a new look at an old problem. Circulation 116, 782-792. doi: 10.1161/CIRCULATIONAHA.106.688889

Fox, C. S., Parise, H., D’Agostino, R. B., Lloyd-Jones, D. M. Sr., Vasan, R. S., Wang, T. J., et al. (2004). Parental atrial fibrillation as a risk factor for atrial fibrillation in offspring. JAMA 291, 2851-2855. doi: 10.1001/jama.291.23.2851

Franco, D., and Campione, M. (2003). The role of Pitx2 during cardiac development. Linking left-right signaling and congenital heart diseases. Trends Cardiovasc. Med. 13, 157-163. doi: 10.1016/s1050-1738(03)00039-2

Franco, D., Chinchilla, A., Daimi, H., Dominguez, J. N., and Aranega, A. (2011). Modulation of conductive elements by Pitx2 and their impact on atrial arrhythmogenesis. Cardiovasc. Res. 91, 223-231. doi: 10.1093/cvr/cvr078

Fye, W. B. (2006). Tracing atrial fibrillation-100 years. N. Engl. J. Med. 355, 1412-1414. doi: 10.1056/NEJMp068059

Go, A. S., Hylek, E. M., Phillips, K. A., Chang, Y., Henault, L. E., Selby, J. V., et al. (2001). Prevalence of diagnosed atrial fibrillation in adults: national implications for rhythm management and stroke prevention: the Anticoagulation and Risk Factors in Atrial Fibrillation (ATRIA) Study. JAMA 285, 2370-2375. doi: 10.1001/jama.285. 18.2370

Gudbjartsson, D. F., Arnar, D. O., Helgadottir, A., Gretarsdottir, S., Holm, H., Sigurdsson, A., et al. (2007). Variants conferring risk of atrial fibrillation on chromosome 4q25. Nature 448, 353-357. doi: 10.1038/nature06007

Kaab, S., Darbar, D., van Noord, C., Dupuis, J., Pfeufer, A., Newton-Cheh, C., et al. (2009). Large scale replication and meta-analysis of variants on chromosome 4q25 associated with atrial fibrillation. Eur. Heart J. 30, 813-819. doi: 10.1093/eurheartj/ehn578

Kannel, W. B., Wolf, P. A., Benjamin, E. J., and Levy, D. (1998). Prevalence, incidence, prognosis, and predisposing conditions for atrial fibrillation: population-based estimates. Am. J. Cardiol. 82, 2N-9N. doi: 10.1016/S0002-9149(98)00583-9

Kim, M. H., Johnston, S. S., Chu, B. C., Dalal, M. R., and Schulman, K. L. (2011). Estimation of total incremental health care costs in patients with atrial fibrillation in the United States. Circ. Cardiovasc. Qual. Outcomes 4, 313-320. doi: 10.1161/CIRCOUTCOMES.110.958165

Kirchhof, P., Kahr, P. C., Kaese, S., Piccini, I., Vokshi, I., Scheld, H. H., et al. (2011). PITX2c is expressed in the adult left atrium, and reducing Pitx2c expression promotes atrial fibrillation inducibility and complex changes in gene expression. Circ. Cardiovasc. Genet. 4, 123-133. doi: 10.1161/CIRCGENETICS.110.958058

Krahn, A. D., Manfreda, J., Tate, R. B., Mathewson, F. A., and Cuddy, T. E. (1995). The natural history of atrial fibrillation: incidence, risk factors, and prognosis in the Manitoba Follow-Up Study. Am. J. Med. 98, 476-484. doi: 10.1016/S00029343(99)80348-9 
Lin, C. R., Kioussi, C., O'Connell, S., Briata, P., Szeto, D., Liu, F., et al. (1999). Pitx2 regulates lung asymmetry, cardiac positioning and pituitary and tooth morphogenesis. Nature 401, 279-282. doi: $10.1038 / 45803$

Liu, X., Wang, F., Knight, A. C., Zhao, J., and Xiao, J. (2012). Common variants for atrial fibrillation: results from genome-wide association studies. Hum. Genet. 131, 33-39. doi: 10.1007/s00439011-1052-3

Lloyd-Jones, D. M., Wang, T. J., Leip, E. P., Larson, M. G., Levy, D., Vasan, R. S., et al. (2004). Lifetime risk for development of atrial fibrillation: the Framingham Heart Study. Circulation 110, 1042-1046. doi: 10.1161/01.CIR.0000140263.20897.42

Mahida, S. (2014). Transcription factors and atrial fibrillation. Cardiovasc. Res. 101, 194-202. doi: $10.1093 / \mathrm{cvr} / \mathrm{cvt} 261$

Mestroni, L. (2003). Genomic medicine and atrial fibrillation. J. Am. Coll. Cardiol. 41, 2193-2196. doi: 10.1016/S0735-1097(03)00459-5

Mommersteeg, M. T., Brown, N. A., Prall, O. W., de Gier-de Vries, C., Harvey, R. P., Moorman, A. F., et al. (2007). Pitx2c and $\mathrm{Nkx} 2-5$ are required for the formation and identity of the pulmonary myocardium. Circ. Res. 101, 902-909. doi: 10.1161/CIRCRESAHA.107.161182

Nattel, S. (2002). New ideas about atrial fibrillation 50 years on. Nature 415, 219-226. doi: $10.1038 / 415219 a$

Otway, R., Vandenberg, J. I., Guo, G., Varghese, A., Castro, M. L., Liu, J., et al. (2007). Stretch-sensitive KCNQ1 mutation A link between genetic and environmental factors in the pathogenesis of atrial fibrillation? J. Am. Coll. Cardiol. 49, 578-586. doi: 10.1016/j.jacc.2006.09.044

Parvez, B., Shoemaker, M. B., Muhammad, R., Richardson, R., Jiang, L., Blair, M. A., et al. (2013). Common genetic polymorphism at 4 q25 locus predicts atrial fibrillation recurrence after successful cardioversion. Heart Rhythm 10, 849-855. doi: 10.1016/j.hrthm. 2013.02.018
Parvez, B., Vaglio, J., Rowan, S., Muhammad, R., Kucera, G., Stubblefield, T., et al. (2012). Symptomatic response to antiarrhythmic drug therapy is modulated by a common single nucleotide polymorphism in atrial fibrillation. J. Am. Coll. Cardiol. 60, 539-545. doi: 10.1016/j.jacc.2012.01.070

Piccini, J. P., Hammill, B. G., Sinner, M. F., Jensen, P. N., Hernandez, A. F., Heckbert, S. R., et al. (2012). Incidence and prevalence of atrial fibrillation and associated mortality among Medicare beneficiaries, 1993-2007. Circ. Cardiovasc. Qual. Outcomes 5, 85-93. doi: 10.1161/CIRCOUTCOMES.111.962688

Roberts, J. D., and Gollob, M. H. (2010). Impact of genetic discoveries on the classification of lone atrial fibrillation. J. Am. Coll. Cardiol. 55, 705-712. doi: 10.1016/j.jacc.2009.12.005

Schweickert, A., Campione, M., Steinbeisser, H., and Blum, M. (2000). Pitx2 isoforms: involvement of Pitx2c but not Pitx2a or Pitx2b in vertebrate left-right asymmetry. Mech. Dev. 90, 41-51. doi: 10.1016/s0925-4773(99)00227-0

Sinner, M. F., Ellinor, P. T., Meitinger, T., Benjamin, E. J., and Kaab, S. (2011). Genome-wide association studies of atrial fibrillation: past, present, and future. Cardiovasc. Res. 89, 701-709. doi: $10.1093 / \mathrm{cvr} / \mathrm{cvr} 001$

Tao, Y., Zhang, M., Li, L., Bai, Y., Zhou, Y., Moon, A. M., et al. (2014). Pitx2, and atrial fibrillation predisposition gene, directly regulates ion transport and intercalated disc genes. Circ. Cardiovasc. Genet. 7, 23-32. doi: 10.1161/CIRCGENETICS.113.000259

Tsai, C. T., Lai, L. P., Hwang, J. J., Lin, J. L., and Chiang, F. T. (2008). Molecular genetics of atrial fibrillation. J. Am. Coll. Cardiol. 52, 241-250. doi: 10.1016/j.jacc.2008.02.072

Wang, J., Klysik, E., Sood, S., Johnson, R. L., Wehrens, X. H., and Martin, J. F. (2010). Pitx2 prevents susceptibility to atrial arrhythmias by inhibiting left-sided pacemaker specification. Proc. Natl. Acad. Sci. U.S.A. 107, 9753-9758. doi: 10.1073/pnas.0912585107
Wang, J., Xin, Y. F., Xu, W. J., Liu, Z. M., Qiu, X. B., Qu, X. K., et al. (2013). Prevalence and spectrum of PITX2c mutations associated with congenital heart disease. DNA Cell. Biol. 32, 708-716. doi: 10.1089/dna.2013.2185

Wolf, P. A., Abbott, R. D., and Kannel, W. B. (1991). Atrial fibrillation as an independent risk factor for stroke: the Framingham Study. Stroke 22, 983-988. doi: 10.1161/01.STR.22.8.983

Xiao, J., Liang, D., and Chen, Y. H. (2011). The genetics of atrial fibrillation: from the bench to the bedside. Annu. Rev. Genomics Hum. Genet. 12, 73-96. doi: 10.1146/annurev-genom-082410101515

Zhou, Z., and Hu, D. (2008). An epidemiological study on the prevalence of atrial fibrillation in the Chinese population of mainland China. J. Epidemiol. 18, 209-216. doi: 10.2188/jea.JE2008021

Conflict of Interest Statement: The authors declare that the research was conducted in the absence of any commercial or financial relationships that could be construed as a potential conflict of interest.

Received: 25 February 2014; accepted: 24 March 2014; published online: 16 April 2014.

Citation: Yao M, Cao Y, Zhu H, Chen Y, Zhu T and Xiao J (2014) Paired-like homeodomain 2: a novel therapeutic target for atrial fibrillation?. Front. Genet. 5:74. doi: 10.3389/fgene.2014.00074

This article was submitted to Epigenomics and Epigenetics, a section of the journal Frontiers in Genetics.

Copyright (c) 2014 Yao, Cao, Zhu, Chen, Zhu and Xiao. This is an open-access article distributed under the terms of the Creative Commons Attribution License (CC BY). The use, distribution or reproduction in other forums is permitted, provided the original author(s) or licensor are credited and that the original publication in this journal is cited, in accordance with accepted academic practice. No use, distribution or reproduction is permitted which does not comply with these terms. 